\title{
Characteristics of an Equitable Instructional Methodology for Courses in Interactive Media
}

\author{
Frank Kurzel \\ University of South Australia, Adelaide, SA, Australia
}

frank.kurzel@unisa.edu.au

\begin{abstract}
This paper focuses on an action research that was conducted to address difficulties with the development of multimedia applications. These difficulties were associated with the programming (scripting) parts of the development environment that were required to create the interactive elements within them. Initially, a learning environment based on adaptive hypermedia was constructed to provide for students with different backgrounds. Unfortunately a large amount of the content that was developed became redundant when the development software changed.
\end{abstract}

Anecdotally, I was aware of these difficulties, but an analysis of questionnaire data that had been collected at the end of each course offerings, revealed a Difficulty factor that could be reduced to a value. When we looked at this figure for arts and then computing students, we found that arts students found these elements significantly more difficult than the computing. This in itself was expected but their respective values provided a metric to use in future evaluations.

What followed was a longitudinal study that involved an action research to resolve the difference in this metric; the result hopefully being that students managed the development environment irrespective of their background. This involved presenting the framework for the development in a more abstract way so that global commands could be planned by the group and then used within individually created sections.

A project based instructional methodology suited this course and authentic projects were used. Students were expected to engage in all aspects of the project, including the interactive elements. We avoided the situation where the arts group member became responsible for the graphic design alone. Peer review and peer assessment were embedded within the course to ensure that students maintained their engagement and got meaningful feedback that could be included in their projects.

The instructional methods used resulted in there being an emphasis on all the parts of the project, and a subsequent valuing of all the components required for the project's completion.

Keywords: game development, instructional methodologies, project based learning, peer assess-

Material published as part of this publication, either on-line or in print, is copyrighted by the Informing Science Institute. Permission to make digital or paper copy of part or all of these works for personal or classroom use is granted without fee provided that the copies are not made or distributed for profit or commercial advantage AND that copies 1) bear this notice in full and 2) give the full citation on the first page. It is permissible to abstract these works so long as credit is given. To copy in all other cases or to republish or to post on a server or to redistribute to lists requires specific permission and payment of a fee. Contact Publisher@InformingScience.org to request redistribution permission. ment, peer review, Flash.

\section{Introduction}

It is the goal of tertiary institutions to provide an equal footing for all students irrespective of their background. Treating students as individuals with different skills and abilities becomes problematic with large classes especially where the students come from different programs. 
Students come into the interactive media major course offerings from a range of areas including computing, media arts, and education and others. With this in mind, I began my investigation into learning environments and instructional methodologies that could hopefully cater for these differences.

Universities have embraced online learning among all faculties and the multimedia studies department of which I was a member had been involved in developing materials for courses prior to the advent of a university wide system. Even with the introduction of a universal system, online facilities, as Twigg (2003, p. 38) noted, "individualized faculty practice ... and standardized the student learning experience." He outlined that we treated all students in the course as if their learning needs, interests, and abilities were the same while the opposite needed to be done: we needed to individualize student learning and standardize faculty practice.

The World Wide Web (WWW) was seen as a vehicle for the development of learning environments that could cater to the expectations and learning styles of students from different cultures and backgrounds. Online course materials supported traditional lectures and tutorials initially; some replaced them.

\section{Background}

Typically, the educational systems were coarse-grained in nature, which limited the reusability of course materials and required rewrites when any changes were made. The instructional methodologies employed were tightly coupled to the content, making it difficult for the teacher to alter the learning theory that might be employed in the delivery; for example, changing to a project based instructional strategy required significant alterations to the materials. Personalising the instruction to take into account prior knowledge, or indeed learning style, was difficult.

Hypertext and hypermedia systems were thought of as the foundational technology to support student centred learning, where the teacher could organise materials hypertextually and the student could make the decision on following the associative link. It was argued (Eklund \& Brusilovsky, 1998) that Adaptive Hypermedia (AH) had the potential to individualise instruction in higher education. Brusilovsky, Eklund, and Schwarz (1996) demonstrated personalising features that could account for individual differences in knowledge. Brusilovsky (2000) used the term concept when referring to the elementary pieces of knowledge within a domain. These were later to be called fine grained learning objects (Wiley, 2001).

Adaptive hypermedia was derived from Intelligent Tutoring Systems (ITS); these are formed with an expert system and a communication module. The expert system accounts for the student history, the pedagogical model, and the domain knowledge. AH systems provide adaptive navigation support through hypertext/hypermedia pages by coupling and maintaining a student profile with the domain model. Expressing this intersection with navigational notations provided a mechanism for the individualised administration of content. Links could be hidden by the system or annotated to provide student course information. An alternate feature known as adaptive presentation provided the ability to present different content.

Personalised learning environments based on AH offered a technology that might account for some of the learning difficulties encountered by providing a hypermedia/multimedia learning platform that had:

- adaptive characteristics driven by an student overlay model

- a range of tools to support student centred learning

- instructional modules constituting the domain knowledge.

This was the technological setting when I embarked on the action research to address anecdotal differences in the way students developed the interactive elements within multimedia courses that 
I was responsible for. Arts students generally managed the graphical elements of any group project work well but had difficulties with the interactive elements. A personalised adaptive learning environment solution appeared to offer promise for realising the goal of providing individualised instruction.

\section{Course Characteristics}

Courses in multimedia usually involve creating digital artifacts and computer applications using development environments (software) that allow the structuring of:

- text - static and dynamic

- images - raster and vector

- animations $-2 \mathrm{D}$ and $3 \mathrm{D}$

- $\quad$ sound - sound affects, voice-overs and music

- $\quad$ video with controls

- Instructions (scripts) to control the application.

Initially, the software used was Macromedia Director, which used a movie metaphor where the media elements were placed into a timeline that a play head processed. The programming language available to control the interactions with media elements like buttons and the navigation along the main timeline was called Lingo. This was an event driven, object oriented language that used behaviours (series of functions or methods driven by user events) to produce the interactivity.

More recently, Flash has been used; Director was abandoned by Adobe after it purchased Macromedia. It, too, is timeline based, and the programming language involved is known as actionScript. The latest version of Flash CS5 uses actionScript 3; its predecessors were interpreted languages and did not employ the strict typing that exists in actionScript 3 . It also has integrated the notion of a class into the development environment, enabling movieClips (modules with their own timelines) to be associated with class definitions that define their behaviour.

The goal of this technology is to provide an environment that enhances the communication between the computer and the human. In an instructional sense, Mayer (2001) talked of the multimedia principle where "people learn better from words and pictures than from words alone." This further elaborated into the Cognitive Theory of Multimedia Learning where "multimedia narration and graphical images produce verbal and mental representations, which integrate with prior knowledge to construct new knowledge."

Interactivity is more than the user's ability to navigate and control media components; it involves a two-way communication between the interactive element and the user. Activities between humans that are interactive include games, conversations, and storytelling, to name a few. There are different levels of interactivity ranging from simple page turning to immersive virtual reality. In almost all instances the quality of an application is determined by its level of interactivity; that is, the more interactive it is, the better it is. Shedroff $(2000$, p.283) also notes that interactivity is a spectrum that proceeds from passive to active.

He outlines that there are a number of components to interactivity, each displaying a range of values. These components include:

- feedback

- control - simple to sophisticated, audience control

- productivity - creation tools

- creativity, co-creativity

- communications - chats, forums, live documents

- adaptivity - personalisation, pseudo-intelligence, etc. 
Interactive multimedia then refers to the integration of multiple media items combined in an application to hopefully increase the impact of the message by providing a range of two way communication structures and responses approaching those that we would equate to activities between humans.

To create these interactions in games, for example, we typically need to involve the scripting (programming) that is provided in the development environment. Given that the students come from non programming backgrounds, this is always an issue. Courses in interactive multimedia invariably include some scripting to establish the interactive elements that might involve:

- managing dynamic dialogue

- controlling navigation and media

- maintaining game and player profiles

- $\quad$ sensing interactions

- using profiles to dynamically alter outcomes

Another complication is in the structuring of the solution where all group members need to work collaboratively in a constructive way so that what they produce can be combined to complete the application. This generally involves group discussions about how the state of play can be stored and communicated as the application is being used.

\section{The Method}

The methodology to account for these difficulties has involved action research; Baskerville (1997) contends that action research involves social processes that can be "studied best by introducing changes into these processes and observing the effects of these changes." Further; the researcher who is actively involved in the cyclic process linking theory and practice benefits from the process. Figure 1 from Baskerville is taken from information systems research and illustrates its cyclic nature.

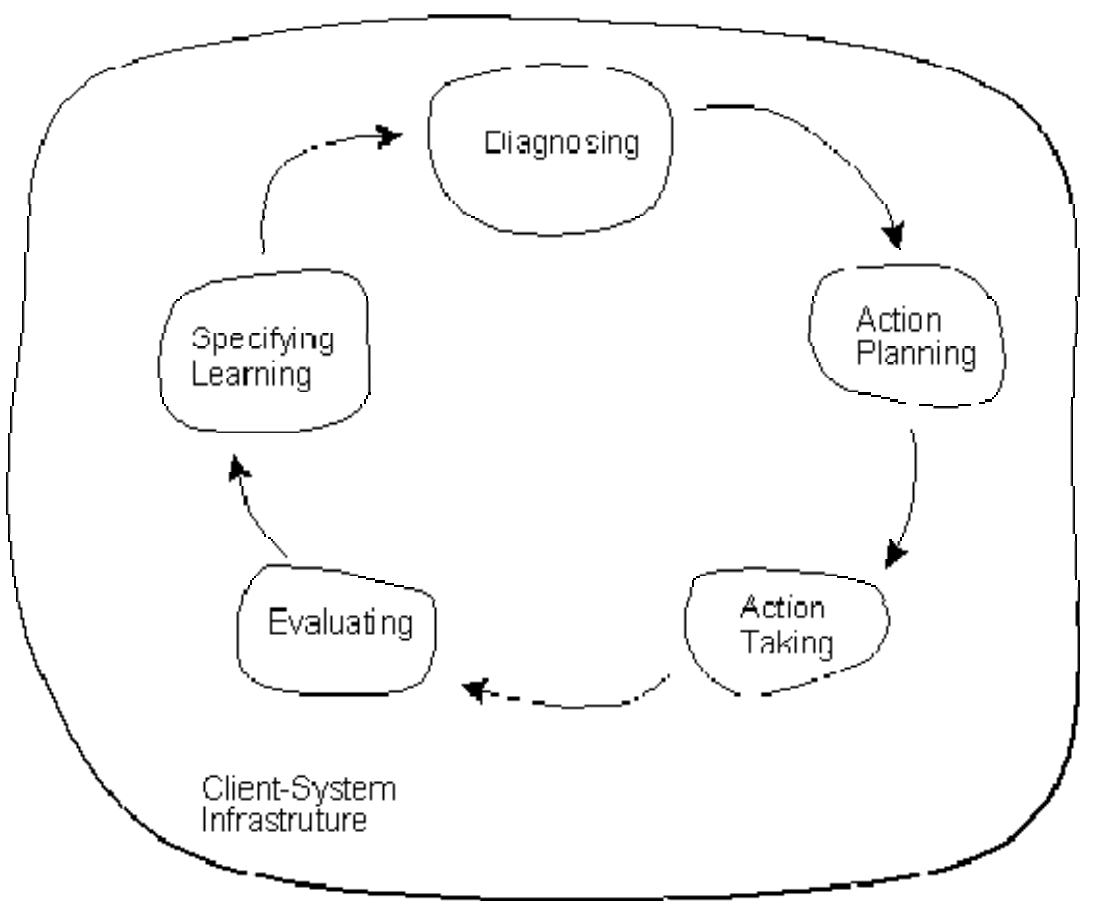

Figure 1: Action Research Methodology (Baskerville 1997) 
The course Creating Interactive Multimedia (INFT2001) is a capstone course in the interactive multimedia stream of the media arts program. It has been the principal focus of my research and aims to expose students to some of the techniques and skills used in constructing multimedia applications. Given that it has been offered on a yearly basis for a number of years, it has provided the opportunity to perform a longitudinal study in an attempt identify issues and subsequently address this disparity in the difficulty encountered in the production of a multimedia projects. With each iteration of this research, the instructional methodology was altered in some way in response to an observed issue and/or some instructional goal that had been decided upon.

The course Interactive Design for Multimedia which precedes Creating Interactive Multimedia in the program sequence used an individual multi-phase project as the major assessment component. At the end of the semester, a questionnaire was administered to collect voluntary feedback from the students. This consisted of twenty-seven Likert Scale questions that were presented online through an in-house online survey system. The response options scored 1 to 5, were strongly agree/ agree/ neutral/ disagree/ strongly disagree.

A factor analysis was applied to the questionnaire and it was apparent that a 3 factor resolution, accounting for $45 \%$ of the overall variance, was appropriate; the factor loadings are shown in the table in Appendix A. On examination of the questionnaire data discussed above, factors that required more consideration were:

- instructional methodology OK,

- group work,

- difficulty encountered.

In the Creating Interactive Multimedia course in the following semester, a similar instructional strategy was used but the students were organised into formal groups of 4 to account for a range of skills. An independent variable indicating the student's program, e.g., computing or media arts, was introduced into a similar questionnaire with 31 items, and a factor analysis was applied.

A two factor resolution accounting for $35 \%$ of the overall variance was appropriate in this case (See Appendix B). The group work factor, which was now part of the methodology, disappeared.

On reducing the InstructionOK and Difficulty factors and then performing a one-way ANOVA, the media arts students reported the work as relatively more difficult than the computing students with means of 2.31 and $3.04, F(1,45)=6.17, p<.001$. Given that this course is situated in the media arts stream, this was significant. Both groups agreed on the acceptability of the instructional methodology with means of 2.24 and 2.37 respectively. This provided my action research with a metric to consider and evaluate subsequent offering. Changes could be made within the instruction of the course and the mean for Difficulty calculated. The goal then was to establish a learning situation that allowed all students to feel equally comfortable with the development environment.

Over the iterations of the course that followed, the difference in the Difficulty metric for the two student groups moved closer together (see Table 1). In 2008 S2, both cohorts of students agreed equally with the notion that the development was difficult, and again in 2009 S2, but to a lesser degree. The difference in the Instruction $O K$ factor remained insignificant in each iteration, suggesting that the project based learning strategy was generally viewed favourably. 
Table 1: Creating Interactive Media (INFT 2001)

Factors 2006-2009

\begin{tabular}{|c|c|c|c|c|c|c|}
\hline Factors & & $\begin{array}{l}2006 \\
\text { S2 }\end{array}$ & $\begin{array}{l}2007 \\
\text { S1 }\end{array}$ & 2008 S1 & $\begin{array}{l}2008 \\
\text { S2 }\end{array}$ & 2009 S2 \\
\hline \multirow{2}{*}{ InstructionOK } & $\begin{array}{l}\text { Media } \\
\text { Arts }\end{array}$ & 2.24 & 2.19 & 2.29 & 2.15 & 2.27 \\
\hline & Computing & 2.37 & 2.34 & 2.52 & 2.44 & 1.89 \\
\hline \multirow{2}{*}{ Difficulty } & \multirow{2}{*}{$\begin{array}{l}\text { Media } \\
\text { Arts Com- } \\
\text { puting }\end{array}$} & 2.31 & 2.39 & 2.24 & 2.24 & 2.68 \\
\hline & & 3.04 & 2.87 & 2.77 & 2.20 & 2.7 \\
\hline
\end{tabular}

The variations in the instruction that might have accounted for this trend will be discussed in the following sections.

\section{Establishing a Learning Environment}

One way of tackling this difference in this perception of Difficulty was to utilise a Learning Management System (LMS) that could enable a tailoring of the instruction to suit a range of student needs. A Multimedia Learning Environment (AMLE) was a Learning Environment (LE) that was designed and developed specifically to provide for these differences in student's backgrounds and multimedia knowledge. AMLE provided direction for both declarative and practical content through annotated links (Brusilovsky, 2000) based on a competency model of the student.

The AMLE session viewer in Figure 2 (Kurzel, 2005) demonstrates a listing of concepts that constituted an Introduction to Multimedia. Notations provided information to the student as to whether the LE viewed that the concept was suitable to be accessed. We chose not to employ link hiding and allow the student to make the decision as to whether they wanted to access the information.

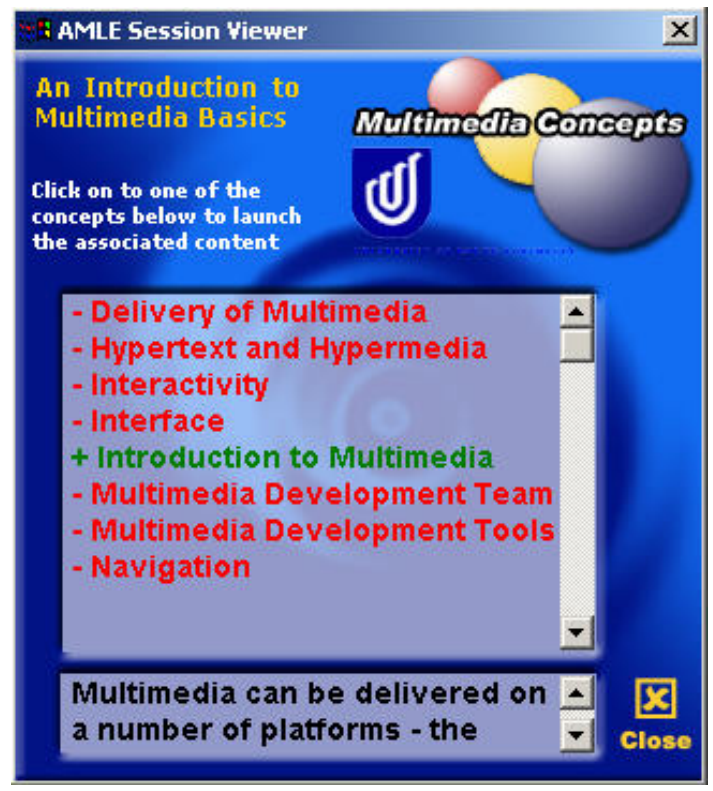

Figure 2: Session Viewer 
Instructor organised groupings of content, as demonstrated above, provided the scaffolding for student interactions with the content. The LE also provided tools to group concepts and allow students to establish their own personalised structures of information. Bookmarking was employed as an effective way of aggregating information. AMLE also provided tools, e.g., search engine and glossary (see Figure 3) (Kurzel, 2005), to locate concepts where required; the Concept Viewer then displayed the content in a range of media formats.

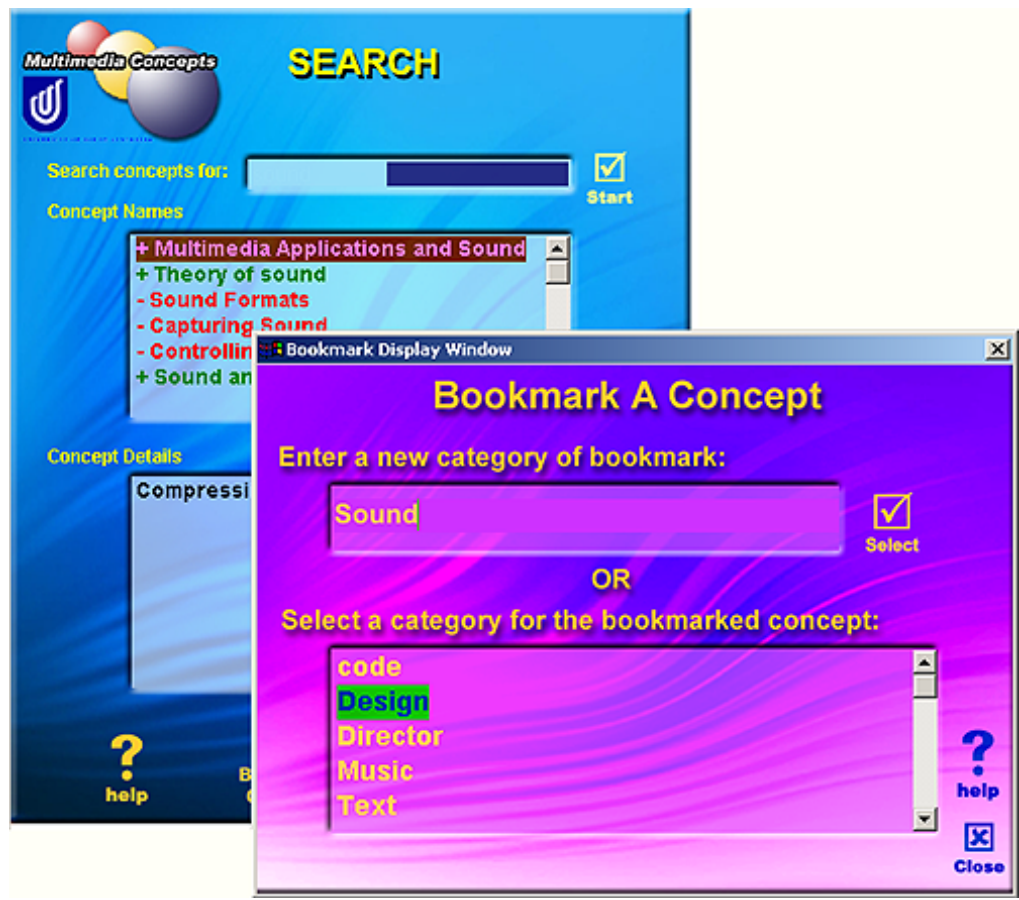

Figure 3: AMLE Tools

To provide for variations in the instructional methodology and to allow the instructor to change from the expository learning framework inherent in the AMLE system, we proposed an architecture that introduced higher level instructional objects that could account for the groupings (sessions as discussed before) and, indeed, any other object that played some role in the methodology (Allert, Dhraief, \& Nejdl, 2002). A course then might be presented by the instructor in different ways, e.g., Creating Interactive Multimedia (Problem Based Learning), or Creating Interactive Multimedia (Expository). The changing of the methodology in theory could also then be extended to the student because the meta-data that supported these fine grained learning objects already existed. (See Figure 4.)

So AMLE had the potential to provide a different learning experience for different students; this might have addressed some of the differences of how they viewed the development environment. 


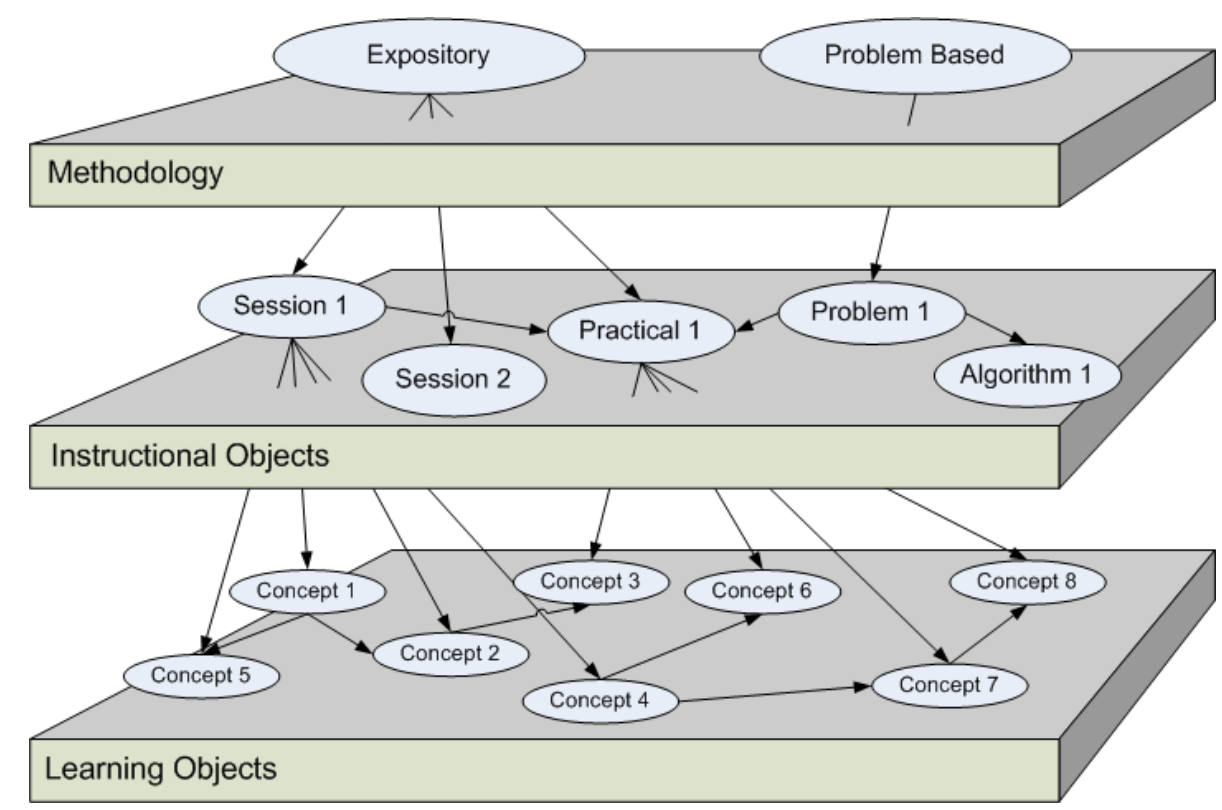

Figure 4: Instructional Framework

\section{Ameliorating Difficulties}

The first semester of 2007 provided another course offering and an opportunity to alter the instruction in an attempt to address this difficulty feature. To avoid the situation where arts students would work on the graphics elements alone and subsequently not be involved in the other aspects of the projects, such as establishing the navigation or the interactive elements, all students needed to have an understanding of how the whole project was structured. This is not to say that they still could not have a major influence in their area of expertise; arts students could still take the major responsibility for the design aspects, and computing students might be responsible for all the interactive elements. An additional individual report outlining the structure of the project was also made part of the overall assessment strategy.

In an attempt to not hide aspects of the interactive techniques required, more was done to outline basic programming aspects through exemplars and discussion. More effort was made to allow students to reflect on script samples posted on the discussion forum and through explanatory internal documentation encouraged within tutorial examples. Students were also encouraged to use the locally developed portal/learning environment (AMLE discussed above) which contained a wealth of information and example scripts on Director techniques. The search and glossary features discussed previously could be used to access the content provided in a range of media formats.

When the 2007 course data was analysed, there was still a difference in the Difficulty factor although it had decreased. The arts students reported the work as more difficult than the computing students with respective means of 2.39 and 2.87; the lower the value, the more the group agreed with the Difficulty proposition. When summative peer assessment data was also reviewed, it became apparent that the computing students (who perhaps were involved in the interactive elements of the project) were being valued more than the arts students in the work that they conducted. This end of course review involved rating other group member's performance including their own focussing on the following:

- professional practice - attendance, punctuality, etc.

- involvement in group decision making and discussions 
- knowledge of the project requirements

- quality of work produced.

More was done to elaborate and highlight the skills and knowledge required and their worth to the final production. A more extensive set of peer assessment questions was presented in the next iteration of the course that was offered in early 2008 to a small group of 20 students. One project group unfortunately was out of step with the others in terms of the quality of the work that was produced for the group's design work for the project; a possible way to handle this, as Falchikov (1996) reported on, might be to introduce peer review.

\section{More Involvement and Engagement}

In a further attempt to address this perceived Difficulty aspect of the course encountered by media arts students, all students were asked to become more involved with the development aspects. Each student took control of an equal section of the project space; they were asked to take responsibility for the design and production of an equal section. In this case, the project involved the creation of a 2D virtual environment where a computer forensic investigation was to be used to solve a crime. The audience for this game was to be 15 year olds and all game tasks were to be simulated.

The group decided on the language of the game play and arrived at words/actions that could be consistently applied throughout the production to achieve the required functionality. They also decided on how the game could be represented internally within project. To solve the crime, for example, evidence would need to be collected requiring the use of an appropriate handler, e.g., addToEvidence(Item). These abstractions were decided on by the group so that each member had some ownership of the game format and their possible use.

The project was organised into components that could be worked on independently, and an agile production model was pursued. Peer review was used with each assessable piece and the feedback from others could be acted upon before marking. The Difficulty factor was again reduced; their means were almost identical (2.24 and 2.20). My interpretation of this was that both cohorts found the development difficult to the same degrees.

\section{Using Flash in Game Development}

By 2009, Director had been superseded by Adobe Flash as the preferred development environment for 2D games and other multimedia artifacts. The content of the learning environment AMLE had become redundant; there were some general concepts that could have been re-used but the majority of it was specific to the development environment and needed a re-write. Most declarative and practical concepts in the AMLE repository would have had an equivalent version within the Flash development environment but the change would have been time consuming. My judgement was that the biggest gains did not come from using AMLE but instead came from the instructional decisions taken. The in-house university wide content delivery system still provided an efficient way of delivering the content, albeit, without any notations to personalise the experience.

Again with this iteration of the course, a game was used as the basis of the project. The Credit Union Christmas Pageant offered sponsorship for the project, provided that the instruction used the Christmas Pageant that is conducted in early November every year, as its theme. The design and production of an interactive game for publishing on the website presented an authentic group project for the students to work on. The game space was subsequently arrived at and divided equally; students took responsibility for their section. The groups decided on this break up along with the navigational structure of the game. A shell of the game was composed of individual 
Flash files developed early in the project. Each student was then able to use game commands within their sections, e.g., addToInvetory(item), to drive the game. The Game Object Model (Amory \& Seagram, 2007) was also used as a framework for the game structure. Most of the interactive elements were accounted for in practical sessions, but some groups also investigated other interactive resources on the WWW.

Hanrahan and Isaccs (2001) have argued that self and peer assessment skills help students develop life long learning skills. The peer and self assessment used in the course provided a good match to the group project work that was being conducted (Wood \& Kurzel, 2008); rubrics elaborating on what the students should consider were used to drive this peer assessment. When the data was collected and the Difficulty factor reduced from the questionnaire data, the two student groups reported the same level of difficulty (2.68 and 2.7).

\section{Conclusion}

The expectation that I have within any multimedia course offering is that all our students should at least feel comfortable with the development environment and appreciate the process that is used in the construction of multimedia applications: in particular, games. I argue that students need this appreciation because they might find themselves working in groups in industry and be placed in the position of project leader. Group project work within this course then is a good match with the goals of this course.

This action research has convinced me that getting students to own equal sections of the project and to then fully appreciate how group decisions on game actions could be used in their sections is vital to their understanding of the process involved. Allowing arts students to avoid the interactive details of a game created the situation where they thought that the environment was difficult to work with and that the work of computing students was worth more that theirs.

The strategy pursued was reliant on the development environment having the ability to modularize the solution so that students could work on components themselves and then bring them together when required. It also required the environment to enable the group to create a game language that involved the abstractions, e.g., addtoInventory(item), addToScore(number), to drive the game and yet not require a knowledge of the full implementation details.

We can not underestimate the value, in an instructional sense, of peer review and assessment. Peer review provided a mechanism where students could see the expected standard of work required for assessment pieces and still have an opportunity to include changes in their work prior to marking. The group projects worked on were all different and so could be discussed and reflected upon collectively. Comments and assessments from other students were taken seriously and self assessment helped in the student's reflection of their own work.

Establishing rubrics that elaborated on the work required for the project helped students to appreciate all components of the work. Each section of the project, from specification to design to implementation, required an elaboration of the profession practice, the standard of work, and an understanding of the requirements of each assessable piece. It resulted in there being an emphasis on all the parts of the project and a subsequent valuing of all the components.

Where problems occurred with interactive components that were not addressed in class, students were encouraged to investigate other available sources. Having an abundance of support materials on the WWW for students to research helped in the development stage because every suggested

interactive element could not be handled by instruction alone. Life-long learning skills are obviously associated with investigations to satisfy problems encountered. Collaborating on solutions to problems in group and class forums helped in satisfying any problems encountered. Finally, working on an authentic project and interacting with industry had the result of engaging the 
groups and encouraging them to use everything at their disposal to meet deadlines to satisfy the project requirements.

\section{References}

Allert, H., Dhraief, H., \& Nejdl, W. (2002). Meta-level category 'role' in metadata standards for learning: Instructional roles and instructional qualities of learning objects. COSIGN-2002, September 2002, University of Augsburg.

Amory, A., \& Seagram, R., (2007), Game object model version II: A theoretical framework for educational game development. South African Journal of Higher Education, 17(2), 206 - 217.

Baskerville, R. (1997). Distinguishing action research from participative case studies. Journal of Systems and Information Technology, 1(1), 25-45.

Brusilovsky, P. (2000) Adaptive hypermedia: From intelligent tutoring systems to web-based education. Proceedings of Intelligent Tutoring Systems'2000, pp.1-7.

Brusilovsky, P., Eklund, P., \& Schwarz, E., (1996). A tool for developing adaptive electronic textbooks on the WWW. Proceedings of WebNet'96, World Conference of the Web Society, San Francisco, CA.

Eklund, J., \& Brusilovsky, P. (1998). Individualising interaction in web-based instructional systems in higher education. AUC Academic Conference, University of Melbourne, Australia.

Falchikov, N. (1996). Improving learning through critical peer feedback and reflection. Paper presented at the Different Approaches: Theory and Practice in Higher Education. Proceedings of HERDSA Conference 1996, Perth WA.

Hanrahan, S. J., \& Isaacs, G. (2001). Assessing self- and peer-assessment: the students' views. Higher Education Research and Development, 20(1), 53-70.

Kurzel, F. (2005). Customizing instruction. Proceedings of the Informing Science and IT Education Conference, InSITE 2005, Flagstaff, Arizona, June 16-19, 2005

Mayer, R. E. (2001). Multimedia learning. New York: Cambridge University Press.

Shedroff, N. (2000). Information interaction design: A unified field theory of design. In R. Jacobson (Ed.), Information design, p.283. MIT Press.

Twigg, C. A. (2003). Improving learning and reducing costs - New models for online learning. EDUCAUSE Review, September/October

Wood, D., \& Kurzel, F. (2008). Engaging students in reflective practice through a process of formative peer review and peer assessment. Proceedings of the ATN Assessment Conference 2008: Engaging Students in Assessment, Adelaide. Retrieved from http://www.ojs.unisa.edu.au/index.php/atna/article/view/376/252

Wiley, D. A., II. (2001). Connecting learning objects to instructional design theory: A definition, a metaphor, and a taxonomy. In D. A. Wiley, The instructional use of learning objects, pp 4-5, Bloomington, IN: 


\section{Appendix A}

Learning Environment Scale: Obimin Rotation Loadings

\begin{tabular}{|c|c|c|}
\hline Factor 1 & Instructional Methodology is OK (eigen 5.219 , variance 20.878 ) & Loadings \\
\hline 11 & I achieved more in this course than I thought I initially would & .791 \\
\hline 19 & $\begin{array}{l}\text { The instructional methodology provided me with enough scope to display } \\
\text { my skills }\end{array}$ & .723 \\
\hline 7 & The assessment structure matched the structure of the course & .715 \\
\hline 2 & The project based instruction in this course suited the way I like to learn & 659 \\
\hline 12 & $\begin{array}{l}\text { The setting of weekly goals helped me focus on what needed to be } \\
\text { achieved. }\end{array}$ & .646 \\
\hline 23 & $\begin{array}{l}\text { I found being able to collaborate with my group in practical sessions very } \\
\text { helpful }\end{array}$ & .595 \\
\hline 8 & $\begin{array}{l}\text { The project enabled me to demonstrate the skills that I brought to the } \\
\text { group. }\end{array}$ & .582 \\
\hline 18 & $\begin{array}{l}\text { I was really satisfied with what the group ended up achieving in the pro- } \\
\text { ject work }\end{array}$ & .581 \\
\hline 13 & $\begin{array}{l}\text { I found the course initially challenging but managed to satisfy the project } \\
\text { requirements. }\end{array}$ & .546 \\
\hline 22 & I was given the opportunity to discuss and reflect on my learning & .545 \\
\hline 20 & The resources provided allowed me to satisfy the course requirements & .537 \\
\hline 24 & I enjoyed working on a project that was authentic. & .520 \\
\hline Factor 2 & Difficulty (eigen 3.476, variance 13.903) & \\
\hline 3 & I preferred working on the graphical design aspects of the course & .763 \\
\hline 4 & I preferred working on the programming in the project $(\mathrm{R})$ & .723 \\
\hline 14 & $\begin{array}{l}\text { An online helpdesk would have been helpful when I was working with } \\
\text { Director. }\end{array}$ & .687 \\
\hline 15 & $\begin{array}{l}\text { I have a good understanding of how to use Director to produce multimedia } \\
\text { pieces (R) }\end{array}$ & .621 \\
\hline 17 & $\begin{array}{l}\text { I like to be able to choose between a number of different media formats } \\
\text { representing content. }\end{array}$ & .619 \\
\hline 10 & $\begin{array}{l}\text { I would have liked to have a discussion forum with only my group mem- } \\
\text { bers }\end{array}$ & .519 \\
\hline
\end{tabular}

(a) The response options. Scored 1 to 5, were as follows: strongly agree/ agree/ neutral/ disagree/ strongly disagree.

(b) Items score in reverse are shown by $(\mathrm{R})$.

(c) $\mathrm{n}=50$ 


\section{Appendix B}

\section{Learning Environment Scale: Obimin Rotation Loadings}

\begin{tabular}{|c|c|c|}
\hline Item & Statements & Loadings \\
\hline Factor 1 & Instructional Methodology is OK (eigen 5.219 , variance 20.878 ) & \\
\hline 11 & I achieved more in this course than I thought I initially would & .791 \\
\hline 19 & $\begin{array}{l}\text { The instructional methodology provided me with enough scope to display my } \\
\text { skills }\end{array}$ & .723 \\
\hline 7 & The assessment structure matched the structure of the course & .715 \\
\hline 2 & The project based instruction in this course suited the way I like to learn & .659 \\
\hline 12 & The setting of weekly goals helped me focus on what needed to be achieved. & .646 \\
\hline 23 & $\begin{array}{l}\text { I found being able to collaborate with my group in practical sessions very } \\
\text { helpful }\end{array}$ & .595 \\
\hline 8 & The project enabled me to demonstrate the skills that I brought to the group. & .582 \\
\hline 18 & $\begin{array}{l}\text { I was really satisfied with what the group ended up achieving in the project } \\
\text { work }\end{array}$ & .581 \\
\hline 13 & $\begin{array}{l}\text { I found the course initially challenging but managed to satisfy the project re- } \\
\text { quirements. }\end{array}$ & .546 \\
\hline 22 & I was given the opportunity to discuss and reflect on my learning & .545 \\
\hline 20 & The resources provided allowed me to satisfy the course requirements & .537 \\
\hline 24 & I enjoyed working on a project that was authentic. & .520 \\
\hline Factor 2 & Difficulty (eigen 3.476, variance 13.903) & \\
\hline 3 & I preferred working on the graphical design aspects of the course & .763 \\
\hline 4 & I preferred working on the programming in the project $(\mathrm{R})$ & .723 \\
\hline 14 & $\begin{array}{l}\text { An online helpdesk would have been helpful when I was working with Direc- } \\
\text { tor. }\end{array}$ & .687 \\
\hline 15 & $\begin{array}{l}\text { I have a good understanding of how to use Director to produce multimedia } \\
\text { pieces }(\mathrm{R})\end{array}$ & .621 \\
\hline 17 & $\begin{array}{l}\text { I like to be able to choose between a number of different media formats rep- } \\
\text { resenting content. }\end{array}$ & .619 \\
\hline 10 & I would have liked to have a discussion forum with only my group members & .519 \\
\hline
\end{tabular}

(a) The response options. Scored 1 to 5: strongly agree/ agree/ neutral/ disagree/ strongly disagree.

(b) Items score in reverse are shown by $(\mathrm{R})$.

(c) $n=50$ 


\section{Biography}

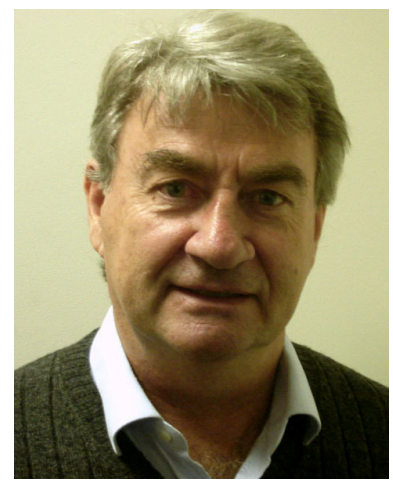

Frank Kurzel is a lecturer in the School of Communication, International Studies and Language at the University of South Australia and he is currently a Program Director for the Bachelor of Media Arts. He has had extensive experience in Education, Computer Science and Multimedia areas. His research interests include web-based instructional systems to support his teaching, and interactive environments. $\mathrm{He}$ is also interested in instructional methodologies and enhancing his teaching through project based learning focusing on game development. 